\title{
Further Validation of a Portuguese Version of the Brief Pain Inventory Interference Scale
}

\section{Contribución Adicional para la Validación de la Versión Portuguesa de la Escala de Interferencia del Inventario Breve de Dolor}

\author{
M. Alexandra Ferreira-Valente \\ Universidad do Porto, Portugal
}

\author{
José L. Pais Ribeiro \\ Mark P. Jensen \\ Universidad do Porto, Portugal U. of Washington School of Medicine, USA
}

\begin{abstract}
Chronic pain is a significant health problem which interferes with patients daily functioning and quality of life. Valid and reliable measures of pain-related interference are needed to provide adequate care to patients and monitor changes in pain and functioning over time. This study sought to evaluate the reliability and validity of a Portuguese version of the Brief Pain Inventory (P-BPI) interference scale. Two hundred and fourteen patients with chronic musculoskeletal pain completed the P-BPI, 0-10 NRS of pain intensity, Short Form-12 Health Status Questionnaire (SF-12), Hospital Anxiety and Depression Scale $($ HADS). The P-BPI demonstrated excellent internal consistency (Cronbach's alpha $=.91$ ) and showed moderate associations with the criterion measures (all $r \mathrm{~s} .30$ or larger), supporting its construct validity. Confirmatory factor analysis of the P-BPI items yielded a single factor, further supporting its construct validity. The results provide strong support for the reliability and validity of the P-BPI interference scale.

Keywords: Portuguese Brief Pain Inventory, pain interference, reliability, validity.
\end{abstract}

Resumen. El dolor crónico es un importante problema de salud que afecta al funcionamiento diario de la persona con dolor, a su bienestar psicológico y a la calidad de vida. Con el fin de prestar cuidados sanitarios adecuados, a monitorear los cambios en el dolor y en el funcionamiento y en vista a la investigación transcultural, se necessitan instrumentos válidos y fiables de evaluación de la interferencia del dolor. El objetivo de este estudio es evaluar la fiabilidad y validez de la versión portuguesa de la Escala de Interferencia de lo Brief Pain Inventory (P-BPI). Doscientos catorze participantes con dolor crónico músculoesquelético respondieron al P-BPI, al 0-10 NRS, al Short Form-12 Health Status Questionnaire (SF-12) y al Hospital Anxiety and Depression Scale (HADS). El P-BPI mostró una excelente consistencia interna (alfa de Cronbach $=0.91)$ y correlaciones moderadas con las medidas de critério $(r s \geq 0.30)$. El análisis factorial confirmatorio apoyó la solución de un factor. Los resultados apoyan la fiabilidad y validez de construto de la Escala de Interferencia del P-BPI. Es necesario que futuras investigaciónes evaluen la responsividad de la escala a los cambios en la interferencia del dolor a lo largo del tiempo.

Palabras clave: Versión portuguesa del Brief Pain Inventory, interferencia del dolor, fiabilidad, validez, estudio instrumental.

Pain is a multidimensional and private experience, defined by the International Association for the Study of Pain (IASP, 2011) as an "...unpleasant sensory and emotional experience associated with

Correspondence on this article should be sent to the first author $\mathrm{M}$. Alexandra Ferreira-Valente, Rua 25 de Abril, n. ${ }^{\circ}$ 5, Idanha-Belas, 2605119 Belas, Portugal. E-mail: mafvalente@gmail.com actual or potential tissue damage, or described in terms of such damage" (International Association for the Study of Pain [IASP], 2011). Although acute pain, persisting for no longer than three months, can be considered important for health and survival (Merskey \& Bogduk, 1994), chronic pain, which persists longer than three months (Merskey \& 
Bogduk, 1994; Miró, Nieto \& Huguet, 2008), results in a complex set of somatic and psychosocial changes that undermines quality of life (Merskey \& Bogduk, 1994; Miró et al., 2008; Pareja, 2008). Chronic pain can come to dominate the patients and his/her family's lives, impacting mobility, muscular strength, daily routines, working ability, mood, interpersonal relationships, sleep, and satisfaction with life (Breivik, Collet, Ventafridda, Cohen, \& Gallacher, 2006; Miró et al., 2008; Morlion et al., 2008; Pareja, 2008; Tunks, Weir, \& Crook, 2008).

Based on a biopsychosocial perspective, and in order to provide adequate care and to be able to monitor changes in key pain-related variables over time, the IMMPACT consensus group (Dworkin et al., 2008) has argued that an adequate evaluation of chronic pain should include different dimensions of the pain experience. These include severity, location and pain's impact or interference on daily living (Crespo \& Rodríguez, 2008; Dworkin et al., 2005), among other medical, psychological and social aspects (Crespo \& Rodríguez, 2008; Dworkin et al., 2005). Thus, for both clinical and research purposes, valid and reliable measures of each of these dimensions of pain experience are needed.

The Brief Pain Inventory (BPI) (Cleeland \& Ryan, 1994) Interference scale is one of the most commonly used measures used to assess pain-related interference and disability. It has proven validity (via correlation with criterion measures: between 0.48 and 0.67 with pain intensity; 0.34 and 0.57 with measures of global physical functioning; 0.41 and 0.52 with measures of global psychological functioning; 0.34 and 0.62 with measures of anxiety and depression) and reliability (Cronbach's alpha between 0.78 and 0.95 ) across multiple languages and cultural groups, and across a broad range of pain conditions (including cancer, multiple sclerosis, spinal cord injury, musculoskeletal conditions, diabetic peripheral neuropathy, herpes zoster and postherpetic neuralgia), for evaluating the impact of pain on daily life (Badia et al., 2003; Caraceni et al., 1996; Cleeland \& Ryan, 1994; Kalyadina et al., 2008; Keller et al., 2004; Mendoza, Mayne, Rublee, \& Cleeland, 2006; Osborne, Raichle, Jensen, Ehde, \& Kraft, 2006; Poulos, Gertz, Pankratz, \& PostWhite, 2001; Radbruch et al., 1999; Raichle,
Osborne, Jensen, \& Cardenas, 2006; Saxena, Mendoza, \& Cleeland, 1999; Yun et al., 2004). The factor structure found in the original study yielded a one factor solution and the same factorial structure have been supported in subsequent studies and in the translated versions (Badia et al., 2003; Caraceni et al., 1996; Cleeland \& Ryan, 1994; Kalyadina et al., 2008; Radbruch et al., 1999; Saxena et al., 1999; Yun et al., 2004). Its validity and reliability have been established across a large number of languages, cultures and pain conditions. Its strengths also include its brevity, simplicity and easy administration and scoring even if administered verbally, making the BPI interference scale very useful in both research and clinical settings, enabling crosscountry and cross-cultural comparisons. Moreover, the BPI Pain Interference scale has also been recommended by the IMMPACT consensus group (Dworkin et al., 2008) as one of two validated measures of pain-related impact on functioning for both research and clinic purposes.

Two preliminary studies have examined the psychometric properties of the BPI Interference Scale for the Portuguese populations (Azevedo et al., 2007; Ferreira-Valente, Pais-Ribeiro, \& Jensen, 2010). These studies demonstrated that the P-BPI Interference scale has good reliability (Azevedo et al., 2007; Ferreira-Valente et al., 2010) and criterion validity (Ferreira-Valente et al., 2010). However, additional research is needed to replicate these findings and confirm the factor structure in a sample of Portuguese individuals with chronic pain, as well as to provide further cross-cultural validation of the measure to enable use in cross-cultural research.

The purpose of this study is to provide further validation of the Portuguese version of the BPI Interference Scale to enable its use in clinical and cross-cultural studies. Based on previous research with the BPI in other samples, we hypothesized that: (1) a confirmatory factor analysis of the P-BPI interference items would yield one factor that explains a substantial portion of the variance in the items; (2) the internal consistency (Cronbach's alpha) of the Portuguese version of the BPI (P-BPI) would be good to excellent (above .80) (Nunnally \& Bernstein, 1994); and (3) the concurrent validity of the PBPI would be supported via a pattern of significant 
moderate to strong (i.e., .30 or larger) correlation coefficients with pain intensity ratings and with measures of physical and psychological functioning.

\section{Methods}

\section{Participants}

Two-hundred and fourteen patients, over 18 years old, with chronic musculoskeletal pain of seven health care institutions in northern and central Portugal completed the study protocol. The sample age ranged between 22 and 88 years old $(M=60.18$, $S D=14.89), 64.7 \%$ were married or living with a significant other and $66.1 \%$ were female. Most participants had a history of chronic pain for at least two years $(71.4 \%)$, and $38.2 \%$ reported having had pain for more than 10 years.

\section{Measures}

Demographic (e.g. age, sex, marital status, level of education, professional status) and pain history information (duration, location and cause) were assessed. Participants also rated their pain intensity in its maximum, minimum and on average during the previous 24hours on 0 to 10 Numerical Rating Scales (NRS). Research supports the validity of the NRS as a measure of pain intensity (Jensen, 2010).

The P-BPI interference scale assesses pain interference across seven daily life activities (i.e. general activity, mood, walking ability, normal work, relations with other people, sleep, and enjoyment of life) on 0 to 10 numerical scales. Research supports the validity and reliability of BPI across different cultures and languages (Cleeland \& Ryan, 1994). Author's permission for use of the BPI was obtained.

The Portuguese SF-12 (Pais-Ribeiro, 2005) was used to assess perceived health status. The SF-12 is scored to assess two health status domains: Physical (Physical Component Summary, PCS) and Psychological (Mental Component Summary, MCS) functioning. The Portuguese version has shown satisfactory reliability and validity (Pais-Ribeiro, 2005). The Portuguese version of the Hospital
Anxiety and Depression Scale (HADS; Pais-Ribeiro et al., 2007) was used as measure of psychological functioning. It asks respondents to rate the severity of 14 depressive or anxiety symptoms on 4-point Likert scales, and has demonstrated good reliability and validity (Pais-Ribeiro et al., 2007).

\section{Procedures}

After signing a consent form, all participants were invited to complete all of the study measures. Subjects who were unable to read or write were assisted by the investigators in completing the measures.

\section{Data Analysis}

Statistical analyses were performed using software PASW Statistics 18. Means and standard deviations for study variables were computed for descriptive purposes. We then performed confirmatory factor analysis (CFA) using EQS V6.1 (Bentler $\& \mathrm{Wu}, 1995)$ to test a hypothesized one-factor model for the seven BPI interference items, using the Comparative Fit Index (CFI) and Standardized Root Mean Square Residual (SRMR) to determine fit (Byrne, 2005). Finally, internal consistency of the P-BPI was assessed by computing a Cronbach's alpha, and construct validity was evaluated by computing Pearson correlation coefficients between the total P-BPI pain interference score and the criterion measures.

Table 1. Descriptive Statistics Study Variables and Brief Pain Inventory Interference Scale Items

\begin{tabular}{lrr}
\hline & Mean & $S D$ \\
\hline BPI Total Interference scale & 4.27 & 2.50 \\
BPI items & & \\
$\quad$ General activity & 4.86 & 2.83 \\
Mood & 4.08 & 2.96 \\
Walking ability & 4.76 & 2.94 \\
Normal work & 5.04 & 3.02 \\
Relations with people & 2.91 & 3.03 \\
Sleep & 4.35 & 3.41 \\
Enjoyment of life & 3.67 & 3.51 \\
Physical Functioning (SF-12, PCS) & 37.11 & 22.69 \\
Mental Health (SF-12, MCS) & 54.25 & 22.72 \\
Anxiety (HADS-A) & 7.69 & 4.13 \\
Depression (HADS-D) & 6.37 & 3.77 \\
\hline
\end{tabular}


Table 2. Reliability Analyses of Brief Pain Inventory Interference Scale

\begin{tabular}{|c|c|c|c|c|c|}
\hline BPI Total scale or item & Our Sample & $\begin{array}{l}\text { Portuguese } \\
\text { (Ferreira- } \\
\text { Valente et } \\
\text { al., 2010) }\end{array}$ & $\begin{array}{l}\text { Italian } \\
\text { (Caraceni et } \\
\text { al., 1996) }\end{array}$ & $\begin{array}{l}\text { German } \\
\text { (Radbruch } \\
\text { et al., 1999) }\end{array}$ & $\begin{array}{l}\text { Spanish } \\
\text { Badia et } \\
\text { al., 2003) }\end{array}$ \\
\hline \multicolumn{6}{|c|}{ Cronbach's Alpha } \\
\hline \multicolumn{6}{|l|}{ BPI Pain Interference } \\
\hline Total scale & 0.91 & 0.82 & 0.78 & 0.88 & 0.87 \\
\hline \multicolumn{6}{|c|}{ Cronbach's Alpha if item deleted } \\
\hline \multicolumn{6}{|l|}{ BPI Pain Interference } \\
\hline \multicolumn{6}{|l|}{ Items } \\
\hline General Activity & 0.89 & 0.79 & 0.72 & 0.86 & - \\
\hline Mood & 0.89 & 0.78 & 0.75 & 0.85 & - \\
\hline Walking ability & 0.90 & 0.79 & 0.76 & 0.88 & - \\
\hline Normal work & 0.90 & 0.80 & 0.72 & 0.86 & - \\
\hline Relations with people & 0.90 & 0.82 & 0.76 & 0.86 & - \\
\hline Sleep & 0.90 & 0.82 & 0.79 & 0.88 & - \\
\hline Enjoyment of life & 0.90 & 0.79 & 0.72 & 0.87 & - \\
\hline
\end{tabular}

\section{Results}

Table 1 presents the descriptive statistics of the study variables. Participants reported mild to moderate levels of pain-related disability (BPI Interference) $[M(S D)=4.27(2.50)$ on the $0-10$ scale] on average, and moderate pain intensity ratings $[M(S D)$ pain intensity on average $=4.56$ (2.12)]. Mean scores of SF-12 Physical Component Summary $(M=37.11, S D=22.69)$ and SF-12 Mental Component Summary $(M=$ $54.25, S D=22.72)$ indicate significant dysfunction in these areas, relative to published norms for healthy individuals (Pais-Ribeiro, 2005; Ware, Kosinski, \& Keller, 1998). On the other hand, mean scores on the HADS, for anxiety $(M=7.69$, $S D=4.13)$ and depression $(M=6.37, S D=3.77)$, were suggestive of mild anxiety similar to individuals with a variety of medical disorders, and normal ratings of depressive symptoms (Pais-Ribeiro et al., 2007).

The combinational indices for the CFA, in our study, supported a one-factor solution, $\chi^{2}(14)$ $=72.54,(p<0.001), \mathrm{CFI}=0.91 ; \mathrm{SRMR}=0.06$ (Bentler \& Bonett, 1980; Hu \& Bentler, 1999). The P-BPI demonstrated an excellent internal consistency in our sample, with an alpha coefficient of 0.91 , which is comparable to the internal consistency values from other samples (see Table 2). The values of the alpha if individual items are deleted were comparable to the overall alpha, suggesting that no item detracts from the reliability of the measure.

Finally, table 3 presents the Pearson correlation coefficients computed between the BPI Interference Scale score and the criterion variables. Statistically significant positive associations were found between pain interference overall score and the patient ratings of maximum, least, and average pain intensity [ranging between 0.57 and $0.60, p<0.01]$, anxiety $[r=0.43, p<0.001]$ and depression $[r=0.45, p<0.001]$. Furthermore, statistically significant negative association were found between pain interference overall score and SF-12 physical functioning score $[r=-0.61, p<$ $0.001]$ and SF-12 mental health score $[r=-0.63, p$ $<0.001]$.

Table 3. Correlations with Measures of Pain Intensity, Physical Dysfunction and Psychological Functioning

\begin{tabular}{lc}
\hline Scale & BPI Interference Scale \\
\hline Pain Intensity (NRS) & \\
$\quad$ Maximum (last 24 hours) & $0.57^{*}$ \\
Minimum (last 24 hours) & $0.60^{*}$ \\
$\quad$ Average Pain & $0.57^{*}$ \\
Physical Functioning (SF-12, PCS) & $-0.61^{*}$ \\
Mental Health (SF-12, MCS) & $-0.63^{*}$ \\
Anxiety (HADS-A) & $0.43^{*}$ \\
Depression (HADS-D) & $0.45^{*}$ \\
\hline
\end{tabular}

Note: $* \mathrm{p}<0.001$ 


\section{Discussion}

The findings provide strong support for the reliability and validity of the Portuguese BPI Interference scale. The Cronbach's alpha of 0.91 indicates excellent internal consistency (Nunnally \& Bernstein, 1994; Pais-Ribeiro, 2008). This value, similar to those found in the original scale (Cleeland \& Ryan, 1994), and is higher than the one found in the previous studies for the P-BPI interference scale (Azevedo et al., 2007; Ferreira-Valente et al., 2010). The high level of internal consistency is also supported by the results of the factor analysis, which provide supports for a single factor (Bentler \& Bonett, 1980; Hu \& Bentler, 1999).

The confirmatory factor analysis yielding a single factor is consistent with and replicates the findings of the original study as well as previous studies using other translated versions of the BPI Interference scale (Badia et al., 2003; Caraceni et al., 1996; Cleeland \& Ryan, 1994; Kalyadina et al., 2008; Radbruch et al., 1999; Saxena et al., 1999; Yun et al., 2004). This consistent finding suggests the possibility that the domain of pain interference may be a unitary domain. However, it remains possible that, even if the specific BPI Interference items assess a single domain, pain interference may be a multidimensional construct, and the BPI items may not adequately reflect this construct. Recently, for example, Yamashiro and colleagues (2011) described a new measure of pain interference - the Pain Disability Assessment Scale (PDAS) - that assesses three distinct pain interference domains: (1) interference with social activities; (2) interference with activities of daily living, and (3) interference with activities that require the use of the low back. It is possible that the consistent support for a single factor solution to the BPI may be associated with its relative brevity and lack of items that reflect some of the interference domains assessed by lengthier measures. The question regarding whether pain interference is best thought of as a single- or multiple-domain construct may be particularly important if different pain interference domains turn out to have different associations with other key pain-related variables (for example, interference with social activities may have stronger associations with meas- ures of psychological functioning, while interference with daily activities might have stronger associations with disability) (Yamashiro et al., 2011). Thus, although the BPI is brief, which makes it useful in settings where assessment burden may be an issue, it may lack content validity for assessing more than one pain interference domain. To the extent that clinicians or researchers may want or need to assess more than one interference domain, a measure such as the PDAS might be considered.

All of the correlations coefficients between P-BPI interference scale and criterion measures support the criterion validity of the Portuguese version of the BPI interference scale. Overall, the coefficients are consistent with the guidelines derived from previous studies (Keller et al., 2004; Mendoza et al., 2006; Osborne et al., 2006; Poulos et al., 2001; Radbruch et al., 1999; Raichle et al., 2006), and with the guidelines proposed by Raichle and associates (2006), suggesting that measures of pain interference should be at least moderately associated (correlation coefficients greater than 0.30 ) with pain intensity and physical and psychological functioning. Consistent with previous research anxiety (FerreiraValente, Pais-Ribeiro, \& Jensen, 2011; Keller et al., 2004; Mendoza et al., 2006; Osborne et al., 2006; Poulos et al., 2001; Radbruch et al., 1999; Raichle et al., 2006), pain interference is strongly correlated with pain intensity, physical and psychological functioning and mood, with patients with higher pain interference having higher levels of pain intensity, worse physical and psychological functioning, and higher levels of depression and anxiety. These findings suggest the importance of pain interference as a predictor of psychological functioning and patients' quality of life and health perception. Considered together with previous studies conducted in different pain conditions, languages and cultures, the results also suggest that the concept and effects of pain interference might generalize across countries.

One important limitation of this study was the use of a cross-sectional design. Because all measures were administered only once, we were not able to evaluate the test-retest stability of the P-BPI over time. Second, we could not determine how representative of the population of patients in Portugal with chronic musculoskeletal pain the sample is. Thus, 
future research is needed to help establish the generalizability of the findings. Finally, we administered only one measure of pain-related interference in this study, which does not allow us to establish the convergent validity of the measure. Additional research addressing this issue is, therefore, needed.

\section{Conclusion}

Despite the study limitations, the findings support the use of the P-BPI in clinical samples. The availability of a validated measure of pain interference for use in individuals who speak Portuguese will contribute to the ability of Portuguese researchers to determine the effects of treatments on the critical outcome domain of pain interference, and compare findings among patients in Portugal to those from samples in other parts of the world.

\section{Acknowledgments}

M. Alexandra Ferreira-Valente has received $\mathrm{PhD}$ grant SFRH/BD/ 40956/2007 in the past year from the Portuguese Foundation for Science and Technology. None of the authors have any conflicts of interest with respect to this study.

\section{References}

Azevedo, L. F., Pereira, A. C., Dias, C., Agualusa, L., Lemos, L., Romão, J., ... Castro-Lopes, J. M. (2007). Tradução, adaptação cultural e estudo multicêntrico de validação de instrumentos para rastreio e avaliação do impacto da dor crónica. Dor, 15, 6-37.

Badia, X., Muriel, C., Gracia, A., Nunez-Olarte, J. M., Perulero, N., Galvez, R., ... Cleeland, C. S. (2003). [Validation of the Spanish version of the Brief Pain Inventory in patients with oncological pain]. Medicina Clinica (Barcelona), 120, 52-59.

Bentler, P. M., \& Bonett, D. G. (1980). Significance tests and goodness-of-fit in the analysis of covariance structures. Psychological Bulletin, 88, 588606.
Bentler, P. M., \& Wu, E. J. C. (1995). EQS/Windows user's guide. Los Angeles, CA: BMDP Statis-tical Software.

Breivik, H., Collet, B., Ventafridda, V., Cohen, R., \& Gallacher, D. (2006). Survey of chronic pain in Europe: Prevalence, impact on daily life, and treatment. European Journal of Pain, 10(4), 287333. doi:10.1016/j.ejpain.2005.06.009

Byrne B. (2005). Factor analytic models: viewing the structure of an assessment instrument from three perspectives. Journal of Personality Assessment, 85, 17-32.

Caraceni, A., Mendoza, T. R., Mencaglia, E., Baratella, C., Edwards, K., Forjaz, M. J., ... Cleeland, C. S. (1996). A validation study of an Italian version of the Brief Pain Inventory (Breve Questionario Per La Valutazione Del Dolore). Pain, 65, 87-92.

Cleeland, C. S., \& Ryan, K. M. (1994). Pain assessment: global use of the Brief Pain Inventory. Annals of the Academy of Medicine, Singapore, 23, 129-138.

Crespo, M. E., \& Rodríguez, J. A. (2008). Evaluación psicológica del dolor. Clínica y Salud, 19, 321-341.

Dworkin, R. H., Turk, D. C., Wyrwich, K. W., Beaton, D., Cleeland, C. S., Farrar, J. T., ... Zavisic, S. (2008). Interpreting the Clinical Importance of Treatment Outcomes in Chronic Pain Clinical Trials: IMMPACT Recommendations. The Journal of Pain, 9, 105-121.

Ferreira-Valente, M. A., Pais-Ribeiro, J. L., \& Jensen, M. P. (2010). Pain-related interference in daily life: Validation of a Portuguese version of the Brief Pain Inventory Interference Scale. In: Cruz, F., Petrus, J. (Eds.). Saúde, Cultura e Sociedade. Actas do 5. Congresso Internacional (pp. 164-181). Viseu: AGIR.

Ferreira-Valente, M., Pais-Ribeiro, J. \& Jensen, M. (2011). Psychosocial factors as predictors of depression and anxiety in patients with chronic pain. European Journal of Pain, 5, 72[Abst].

Hu, L., \& Bentler, P. M. (1999). Cut-off criteria for fit indexes in covariance structure analysis: Conventional criteria versus new alternatives. Structural Equation Modeling, 6, 1-55.

International Association for the Study of Pain. 
(2011). IASP Taxonomy. Retrieved April, 15, 2011 from http://www.iasp-pain.org/AM/Template.cfm?-Section=Pain_Defi...isplay.cfm\&ContentID $=1728$

Jensen, M. P. (2010). Measurement of pain. In Fishman, S. M., Ballantyne, J. C., and Rathmell, J. P. (Eds.), Bonica's management of pain ( $4^{\text {th }}$ ed.) (pp. 251-270). Media, PA: Williams \& Wilkins.

Kalyadina, S. A., Ionova, T. I., Ivanova, M. O., Uspenskaya, O. S., Kishtovich, A.V., Mendoza, T. R., ... Wang, X. S. (2008). Russian Brief Pain Inventory: Validation and application in cancer pain. Journal of Pain and Symptom Management, 35, 95-102.

Keller, S., Bann, C., Dodd, S., Schein, J., Mendoza, T., \& Cleeland, C. (2004). Validity of the Brief Pain Inventory for use in documenting the outcomes of patients with noncancer pain. Clinical Journal of Pain, 20, 309-318.

Mendoza, T., Mayne, T., Rublee, D., \& Cleeland, C. (2006). Reliability and validity of a modified Brief Pain Inventory short form in patients with osteoarthritis. European Journal of Pain, 10, 353361.

Merskey, H., \& Bogduk, N. (Eds) (1994). Classification of chronic pain: descriptions of chronic pain syndromes and definitions of pain terms (2nd ed.). Seattle: IASP Press.

Miró, J., Nieto, R., \& Huguet, A. (2008). Predictive factors of chronic pain and disability in whiplash: A Delphi poll. European Journal of Pain, 12, 3047. doi:10.1016/j.ejpain.2007.02.004

Morlion, B., Walch, H., Yihune, G., VielvoyeKerkmeer, A., de Jong, Z., Castro-Lopes, J., \& Stanton-Hicks, M. (2008). The Pain Associates' International Network Initiative: a novel practical approach to the challenge of chronic pain management in Europe. Pain Practice, 8, 473-480. Doi: 10.1111/j.1533-2500.2008.00236.x

Nunnally, J., \& Bernstein, I. (1994). Psychome-tric Theory ( $3^{\text {rd }}$ ed.). New York: Mcgraw-Hill.

Osborne, T., Raichle, K., Jensen, M., Ehde, D., \& Kraft, G. (2006). The reliability and validity of pain interference measures in persons with multiple sclerosis. Journal of Pain and Symptom Management, 32, 217-229.
Pais-Ribeiro, J. L. (2005). O importante é a saúde: estudo de adaptação de um instrumento para avaliar o estado de saúde. Lisboa: Fundação Merck Sharp \& Dohme.

Pais-Ribeiro, J. L. (2008). Metodologia de investigação em psicologia e saúde ( $2^{\text {nd }}$ ed.). Porto: Legis Editora.

Pais-Ribeiro, J. L., Silva, I., Ferreira, T., Martins, A., Meneses, R., \& Baltar, M. (2007). Validations study of a Portuguese version of the Hospital Anxiety and Depression Scale. Psychology, Health \& Medicine, 12, 225-237.

Pareja, M. A. (2008). Perspectivas en el estudio y tratamiento psicológico del dolor crónico. Clínica y Salud, 19, 417-430.

Poulos, A., Gertz, M., Pankratz, V., \& Post-White, J. (2001). Pain, mood disturbance, and quality of life in patients with multiple myeloma. Oncology Nursing Forum, 28, 1163-1171.

Radbruch, L., Loick, G., Kiencke, P., Lindena, G., Sabatowski, R., Grond, S., ... Cleeland, C. S. (1999). Validation of the German version of the Brief Pain Inventory. Journal of Pain and Symptom Management, 18, 180187.

Raichle, K., Osborne, T., Jensen, M., and Cardenas, D. (2006). The reliability and validity of pain interference measures in persons with spinal cord injury. The Journal of Pain, 7, 179-186.

Saxena, A., Mendoza, T., \& Cleeland, C. (1999). The assessment of cancer pain in north India: The validation of the Hindi Brief Pain Inventory BPI-H. Journal of Pain and Symptom Management, 17, 27-41.

Tunks, E., Weir, R., \& Crook, J. (2008). Epidemiologic Perspective on Chronic Pain Treatment. Canadian Journal of Psychiatry, 53, 235-241.

Ware, J., Kosinski, M., \& Keller, S. (1998). SF-12: How to score the SF-12 Physical and Mental Health Summary scales ( $3^{\text {rd }}$ ed.). Boston, MA: The Health Institute, New England Medical Center.

Yamashiro, K., Arimura, T., Iwaki, R., Jensen, M. P., Kubo, C., \& Hosoi, M. (2011). A multidimensional measure of pain interference: Reliability and validity of the Pain Disability Assessment Scale. Clinical Journal of Pain, 27, 338-343.

Yun, Y. H., Mendoza, T. R., Heo ,D. S., Yoo, T., Heo, 
B. Y., Park, H.A., ... Cleeland, C. S. (2004). Development of a cancer pain assessment tool in
Korea: a validation study of a Korean version of the brief pain inventory. Oncology, 66, 439-444.

Artículo recibido: 01/06/2011

Revisión recibida: 25/11/2011

Aceptado: 01/12/2011 